\title{
CONTROLE DA FERRUGEM DA FOLHA E DA MANCHA BRONZEADA DA FOLHA DE TRIGO PELO USO DE FUNGICIDAS EM TRATAMENTO DE SEMENTES
}

\author{
EDSON C. PICININI \& JOSÉ M. FERNANDES
}

\author{
Embrapa Trigo, Cx. Postal 451, CEP 99001-970, Passo Fundo, RS; e-mail: picinini@cnpt.embrapa.br \& \\ mauricio@cnpt.embrapa.br
}

(Aceito para publicação em 06/06/2000)

Autor para correspondência: Edson C. Picinini

\section{ABSTRACT \\ Wheat leaf rust and tan spot control by seed treatment with fungicides}

The control of leaf rust and tan spot of wheat by seed treatment with fungicides was evaluated during 1998 in Passo Fundo, RS. Except for treatments including triadimenol and iprodione, leaf rust and tan spot severity in abo ve ground parts of wheat plants was drastically reduced by the fluquinconazole fungicide used.
As perdas de rendimento de grãos por doenças na cultura de trigo [Triticum aestivum L. Thell.] são relativamente elevadas, podendo chegar a 44,6\% (Picinini et al., Fitopatologia Brasileira. 21:362. 1996). A eficiência de um fungicida selecionado para o controle de uma doença depende do momento da aplicação e da qualidade da pulverização. Fungicidas que aplicados na semente são translocados para os órgãos aéreos da planta e lá permanecem por um longo período podem oferecer uma proteção prolongada à entrada de patógenos. O controle das doenças fúngicas da parte aérea via tratamento de sementes é uma nova alternativa, que poderá abrir novas perspectivas no controle das doenças em cereais de inverno. O objetivo deste trabalho foi o de avaliar o fungicida fluquinconazole aplicado na semente de trigo, em diferentes doses, para o controle de doenças foliares do trigo. O experimento foi conduzido na Embrapa Trigo, em 1998. Sementes da cultivar BR 43 foram tratadas em laboratório com os fungicidas (em g i.a./100 g de sementes) $+2 \%$ de água: fluquinconazole + procloraz, nas doses de 250,5 g + 51,0 g, $208,7 \mathrm{~g}+42,5 \mathrm{~g}, 167,0 \mathrm{~g}+34,0 \mathrm{~g}$ e $125,5 \mathrm{~g}+25,5 \mathrm{~g}$; fluquinconazole, nas doses de $125,0 \mathrm{~g}$ e $83,5 \mathrm{~g}$; e fluquinconazole ( $250 \mathrm{PM}$ ) nas doses de $187,5 \mathrm{~g}$ e $125,0 \mathrm{~g}$. Os fungicidas triadimenol na dose de 40,0 $\mathrm{g}$ e iprodione, na dose de 50,0 g, foram usados como comparativos, além de uma testemunha, sem fungicida. O delineamento foi blocos ao acaso com quatro repetições e as parcelas possuíam cinco linhas espaçadas de $20 \mathrm{~cm}$ por $5 \mathrm{~m}$ de comprimento. No enchimento dos grãos, todas as parcelas foram pulverizadas com propiconazole (125 g i.a./ha). Avaliou-se a severidade ( $\mathrm{S}=$ percentual da área foliar com sintomas), para a ferrugem da folha, induzida por Puccinia recondita f. sp. tritici Rob. ex. Desm, e para a mancha bronzeada da folha, induzida por Drechslera tritici-repentis (Died.) Drechs. Os componentes de rendimento avaliados foram o rendimento de grãos e o peso do hectolitro. Os resultados mostram que nesses parâmetros, diferenças significativas $(\mathrm{p} \geq 0,05)$ entre os tratamentos foram observadas (Tabela 1). Os valores de severidade determinados aos 104 dias após a semeadura (Tabela 1), revelaram que a severidade de ferrugem da folha era $\leq$ a $18 \%$ em todos os tratamentos com fluquinconazole contrastando com valores $\geq$ $62 \%$ nos tratamentos comparativos. Para a mancha bronzeada, os valores de severidade nos tratamentos com fluquinconazole foram $\leq$ a $3 \%$, contrastando com valores $\geq$ a $34 \%$ nos tratamentos comparativos. Pela primeira vez no Brasil observou-se ao nível de campo, uma eficiência tão longa de um fungicida do grupo dos triazóis em tratamento de sementes no controle da ferrugem da folha e da mancha bronzeada, na parte aérea da cultura de trigo.

TABELA 1 - Efeito de diferentes tratamentos de sementes com fungicidas no rendimento de grãos, no peso do hectolitro e no controle de doenças na parte aérea da cultivar de trigo (Triticum aestivum) BR 43, no ano de 1998. Embrapa Trigo, 2000

\begin{tabular}{|c|c|c|c|c|c|}
\hline \multirow[t]{2}{*}{ Tratamento } & \multirow{2}{*}{$\begin{array}{l}\text { g i.a./100 kg } \\
\text { sementes }\end{array}$} & \multirow{2}{*}{$\begin{array}{l}\text { Rendimento } \\
(\mathrm{kg} / \mathrm{ha})^{1}\end{array}$} & \multirow{2}{*}{$\begin{array}{c}\text { Peso do } \\
\text { hectolitro }\end{array}$} & \multicolumn{2}{|c|}{$\begin{array}{r}\text { Severidade } \\
\text { de Doenças }\end{array}$} \\
\hline & & & & FF & MB \\
\hline Fluquinconazole + Proclc & $250,0+51,0$ & $2.800 \mathrm{a}$ & 71,38 abc & 7 & 2 \\
\hline Fluquinconazole $250 \mathrm{PM}$ & 125,0 & $2.725 a b$ & $73,48 \mathrm{a}$ & 7 & 3 \\
\hline Fluquinconazole & 125,0 & $2.679 \mathrm{ab}$ & $72,30 \mathrm{abc}$ & 12 & 2 \\
\hline Fluquinconazole + Proclc & $125,0+25,5$ & $2.418 \mathrm{bc}$ & $71,55 \mathrm{abc}$ & 2 & 1 \\
\hline Fluquinconazole + Proclc & $167,0+34,0$ & $2.388 \mathrm{bc}$ & 71,18 abcd & 12 & 1 \\
\hline Fluquinconazole + Proclc & $208,7+42,5$ & $2.346 \mathrm{bc}$ & 70,88 abcd & 5 & 1 \\
\hline Fluquinconazole & 83,5 & $2.288 \mathrm{bc}$ & $70,38 \mathrm{bcd}$ & 18 & 3 \\
\hline Fluquinconazole $250 \mathrm{PM}$ & 187,5 & $2.048 \mathrm{c}$ & $72,90 \mathrm{ab}$ & 7 & 2 \\
\hline Triadimenol & 40,0 & $1.560 \mathrm{~d}$ & $68,68 \mathrm{~d}$ & 62 & 34 \\
\hline Iprodione & 50,0 & $1.438 \mathrm{~d}$ & $69,98 \mathrm{~cd}$ & 86 & 37 \\
\hline Testemunha & ----- & $1.299 \mathrm{~d}$ & $69,75 \mathrm{~cd}$ & 63 & 34 \\
\hline CV\% & & 15,07 & 2,54 & & \\
\hline
\end{tabular}

${ }^{1}$ Médias seguidas de mesma letra, não diferem, entre si, pelo teste de Duncan, a $5 \%$.

${ }^{2} \mathrm{FF}=$ Ferrugem da folha (P.recondita $\mathrm{f}$. sp. tritici $) ; \mathrm{MB}=$ Mancha bronzeada (D. tritici-repentis). 